haematogenous. This concept is further substantiated by the response to treatment: simple excision of the abscess and primary suture resulted in a satisfactory recovery in almost all cases.

This rather unusual presentation of tuberculous infection may, understandably, lead to difficulties in diagnosis. In the Birmingham series the correct preoperative diagnosis was recorded in only 6 of the 32 patients, though all were seen by experienced staff. In their early experience the Bradford workers used prolonged immobilization of adjacent joints and an exhaustive search for underlying chronic tuberculosis. However, with increasing experience in both centres it became apparent that no obvious underlying focus was present and that the patients could be treated relatively lightly. Once the diagnosis had been confirmed by aspiration and the patient given antituberculosis drug therapy surgical drainage of the pus was often not required. In the Birmingham report it is stressed that the best form of treatment, if surgery becomes necessary, is excision and primary suture of the abscess. Merely to incise and drain the abscess results in secondary infection, and a sinus that takes a long time to heal.

It is not clear why tuberculous disease in immigrants should behave in a different way from tuberculous disease as we once used to know it in Britain. There is no evidence that the strain of Mycobacterium tuberculosis is any different. General practitioners and casualty officers should be aware of this new-look tuberculous disease, for it is to them that the majority of these patients will come. It is important not only to recognize these lesions before inappropriate treatment is begun but also to recognize the benign natural history of the disease and to protect the patient from overzealous treatment.

Shaw, N. M. and Bassu, A. K., British fournal of Surgery, 1970, 57, 418. Ward, A. S., British fournal of Surgery, in press.

\section{Navel Ills}

In the animal world the umbilical cord and the navel are largely left to look after themselves. The newly born piglet, for example, strains at the cord like a dog on the lead until it snaps, leaving from two to six inches of it still attached to the abdominal wall. This is trailed around through dung and dirt until it shrivels and finally drops off. Infection occasionally gains entry but haemorrhage hardly ever occurs.

In man more positive treatment is required, by tradition at least if not by necessity. The incisive cut of the scissors probably renders the vessels more prone to bleed compared with the stretching and tearing manoeuvre of the piglet, which stimulates the vessels to constrict. The traditional ligaturing of the cord with thread left much to be desired, for the knot became progressively looser as the tissues shrivelled and repeated re-tying was required. Plastic clamps are easier to apply but may act as a lever when accidentally pulled, thereby raising the risk of haemorrhage proximal to it. Latex bands are increasing in popularity, for they have the merit of contracting as the cord stump shrinks and so can be left undisturbed with confidence.

The neonatal umbilicus is a well-known site for staphylococci to colonize, and may act as a reservoir for the spread of infection, which may gain entry to the bloodstream, invade other superficial structures, or be passed on to another baby. Consequently antiseptic dehydrating powders are applied, two popular preparations consisting mainly of talc with a little starch and some hexachlorophane.

D. I. McCallum and G. F. M. Hall ${ }^{1}$ have recently criticized the use of such powders on the ground that the application of talc to a raw surface invites the development of a granuloma. In ten years they have studied no fewer than 18 of these umbilical granulomata; on histological examination these showed inflammatory granulation tissues containing doubly refractile particles and a giant-cell reaction in relation to some of them. Their first two cases were from toddlers with persistent umbilical "tumours"; subsequently they examined polyps from young babies and in three out of six specimens of pyogenic granulomata they found areas of giant-cell foreignbody reaction to talc, though they were unable to decide whether the talc had initiated the lesion or merely perpetuated a primary pyogenic granuloma.

An umbilical polyp which is bright red and firm and has a mucoid secretion and a tendency to bleed, which persists for years, and is unaffected by astringents will probably contain intestinal mucosa as distal remnants of the vitelline duct. The authors found five instances of vitello-intestinal nodules which contained areas of talc granuloma.

For at least a decade talc has been banned for use with surgeons' gloves because of its irritant action on the peritoneum and pleura. Probably its use should also now be abandoned in umbilical preparations, though McCallum and Hall do not specify a suitable substitute. Prepared starch is in general use with surgeons' gloves and has the added advantage that it absorbs water over three times more efficiently than talc. ${ }^{2}$ Nevertheless, starch may cause reactions, though of much less severity than talc. ${ }^{3}$

If this much smaller risk, coupled with much greater efficiency, is still considered unacceptable then some form of antiseptic spray followed by exposure would have to be adopted. But there is much to commend the drying action of a powder such as prepared starch combined with hexachlorophane.

${ }^{1}$ McCallum, D. I., and Hall, G. F. M., British fournal of Dermatology, $1970,83,151$

${ }^{2}$ Rae, J., British fournal of Dermatology and Syphilis, 1950, 62, 319.

Myers, R. N., Deaver, J. M., and Brown, C. E., Annals of Surgery, 1960 $151,106$.

\section{Gynaecology in General Practice}

Surveys of the general practitioner's working day have shown that he spends surprisingly little of his time on gynaecological problems. ${ }^{1}$ Yet most family doctors with skill in this field would acknowledge how often time and care spent on solving apparently minor problems may end a source of nagging unhappiness for a woman. Moreover, the introduction of new drugs and the deeper involvement of many doctors in community medicine now mean that they themselves can deal with problems that once would have had to be referred to specialists-such as trichomonas infection and advising on family planning methods. This week we start a new series of "Medical Practice" articles on gynaecology in general practice, in which experts will discuss the management of various conditions in a domiciliary setting. In this field-as in so many-knowledge is the basis of confidence.

1 Primary Medical Care. London, British Medical Association, 1970. 裏 